\title{
HUBUNGAN PENGAWASAN DENGAN PERILAKU AMAN BURUH BANGUNAN DI KABUPATEN BADUNG TAHUN 2019
}

Kezia Leditia Supardi*, Partha Muliawan

Program Studi Kesehatan Masyarakat, Fakultas Kedokteran, Universitas Udayana

"email: kkezialadytia@yahoo.com

\begin{abstract}
ABSTRAK
Pengawasan merupakan faktor penting yang menguatkan timbulnya perilaku seseorang dalam bekerja. Tujuan dari penelitian ini adalah untuk melihat hubungan pengawasan kesehatan dan keselamatan kerja (K3) dengan perilaku aman (safety behavior) dalam mencegah kecelakaan kerja. Penelitian ini menggunakan metode kuantitatif dengan jenis penelitian analitik menggunakan rancangan cross-sectional. Responden pada penelitian ini berjumlah 213 orang yang dipilih dengan metode systematic random sampling. Hasil penelitian ini menunjukkan bahwa mayoritas responden berperilaku tidak aman (51,64\%). Terdapat hubungan antara pengawasan K3 $(\mathrm{OR}=3,21 ; 95 \% \mathrm{CI}=1,809-5,681 ; \mathrm{p}=0,000)$ dan pengetahuan keselamatan kerja $(\mathrm{OR}=1,88 ; 95 \% \mathrm{CI}=1,049-3,368$; $\mathrm{p}=0,034$ ). Faktor yang paling bermakna dalam mempengaruhi perilaku aman adalah pengawasan K3. Selain itu, responden yang memiliki persepsi pengawasan K3 yang baik maka 3,2 kali akan berperilaku lebih aman dibandingkan responden yang memiliki persepsi pengawasan K3 yang kurang baik. Peneliti menyarankan bagi pekerja untuk selalu menaati peraturan yang ditetapkan oleh perusahaan, pengawas perlu meningkatkan pengawasan dan melakukan monitoring evaluasi terhadap perilaku pekerja supaya terjadi perubahan perilaku.
\end{abstract}

Kata Kunci : Perilaku Aman, Pengawasan, Konstruksi

\begin{abstract}
Supervision is an important factor that reinforces the emergence of a person's behavior at workplace. The purpose of this study is to know the relationship between supervision of occupational health and safety (OHS) and safe behavior in preventing work accidents. This study uses a quantitative method with analytical crossectional approach to determine the relationship of supervision with safety behavior. The subjects of this study were 213 workers selected by systematic random sampling method. The result show $55,87 \%$ has unsafe behavior. There is a relationship between OHS supervision $(\mathrm{OR}=3.21 ; 95 \% \mathrm{CI}=1,809-5,681 ; \mathrm{p}=0,000)$ and occupational safety knowledge $(\mathrm{OR}=1.88 ; 95 \% \mathrm{CI}=1,049-3,368 ; \mathrm{p}=0.034)$. The most significant factor influencing safety behavior is OSH supervision. In addition, respondents who have a good perception of OHS supervision 3.2 times will behave more safely than respondents who have a poor perception of OHS supervision. Suggestion for workers are to always obey the rules set by the company and for supervisors to increase supervision of workerss and conduct monitoring and evaluation of worker's safety behavior.
\end{abstract}

Key Words: Safe Behavior, Supervision, Construction

\section{PENDAHULUAN}

Sektor konstruksi merupakan bagian yang penting dalam pembangunan suatu negara. World Health Organization Regions menyatakan bahwa pada tahun 2015 salah satu penyebab utama kematian di tempat kerja sebesar $14 \%$ diakibatkan oleh kecelakaan di tempat kerja. (Workplace Safety and Health Institute, 2017)

Precede-Proceed Theory yang dicetuskan oleh Green dan Kreuter menyatakan perilaku seseorang ditentukan oleh tiga
Penyebab kecelakaan kerja adalah perilaku tidak aman (unsafe behavior) (88\%), kondisi yang tidak aman (unsafe condition) (10\%), dan tidak diketahui penyebabnya (2\%). (National Safety Council, 2011). Hal ini menunjukkan bahwa faktor perilaku mempengaruhi kejadian kecelakaan di tempat kerja. faktor, yakni predisposing factor, enabling factor dan reinforcing factor. Dimana pengawasan dan motivasi merupakan 
bagian dari reinforcing factor atau disebut juga faktor penguat perubahan perilaku dan pengetahuan merupakan bagian dari faktor predisposisi atau faktor yang mempermudah terjadinya perilaku seseorang. (Notoatmodjo 2012)

Proyek $X$ merupakan proyek konstruksi pembangunan gedung yang terletak di Kabupaten Badung. Proyek ini merupakan proyek pembangunan gedung 4 lantai dengan luas tanah 1.8 hektare dan tinggi gedung 15 meter.

Berdasarkan hasil wawancara peneliti dengan manajemen diketahui masih banyaknya pekerja yang melanggar peraturan kerja seperti merokok di area proyek, memakai APD yang belum standar. Selama masa pembangunan gendung $X$ pernah terjadi kecelakaan kerja sehingga 4 orang pekerja terluka. Kecelakaan tersebut diakibatkan oleh jatuhnya rangka baja yang tengah dipasang dan menimpa crane yang sedang beroperasi.

Berdasarkan uraian di atas, maka penulis tertarik untuk meneliti mengenai hubungan pengawasan kesehatan dan keselamatan kerja dengan perilaku aman (safety behavior) dalam mencegah kecelakaan kerja pada buruh bangunan di Kabupaten Badung.

\section{METODE PENELITIAN}

Penelitian ini menggunakan metode kuantitatif dengan jenis penelitian analitik menggunakan rancangan cross-sectional Populasi terjangkau dalam penelitian ini adalah seluruh pekerja buruh bangunan proyek X di Kabupaten Badung sebanyak 322 orang. Jumlah sampel minimum pada penelitian ini sebanyak 213 responden. Teknik pengambilan sampel menggunakan teknik systematic random sampling.

Instrument penelitian yang peneliti gunakan adalah kuesioner disusun dengan indikator-indikator perilaku aman menurut penelitian Martinez-Corcoles, dkk (2011) dan telah dilakukan uji validitas dan realibitas. Pengambilan data dilakukan menggunakan metode wawancara dengan memberikan lembar persetujuan kepada responden. Analisis kuantitatif data menggunakan tiga analisis data yaitu univariabel, bivariabel dengan uji chi-square, dan multivariable menggunakan uji Binary Logistic Regression dengan metode enter.

\section{HASIL}

Berdasarkan Tabel 1, ditemukan bahwa umur responden pada penelitian ini paling banyak berada pada kelompok umur 25-34 tahun (43,66\%). Mayoritas pekerja buruh bangunan berpendidikan terakhir SMP (65,26\%). Responden mayoritas telah bekerja sebagai buruh bangunan selama 1-5 tahun (45,07\%).

\section{Tabel 1. Gambaran Karakteristik Responden}

\begin{tabular}{lcc}
\hline \multicolumn{1}{c}{ Karakteristik Responden } & Frekuensi (n) & Proporsi (\%) \\
\hline $\begin{array}{l}\text { Umur } \\
\text { 15-24 Tahun }\end{array}$ & 48 & \\
\hline
\end{tabular}




\begin{tabular}{|c|c|c|}
\hline 25-34 Tahun & 93 & 43,66 \\
\hline 35-44 Tahun & 51 & 23,94 \\
\hline 45-54 Tahun & 18 & 8,45 \\
\hline$\geq 55$ Tahun & 3 & 1,41 \\
\hline \multicolumn{3}{|l|}{ Pendidikan } \\
\hline SD & 39 & 18,31 \\
\hline SMP & 100 & 46,95 \\
\hline SMA & 70 & 32,86 \\
\hline Sarjana & 4 & 1,88 \\
\hline \multicolumn{3}{|l|}{ Lama Kerja } \\
\hline 1-5 Tahun & 96 & 45,07 \\
\hline 6-10 Tahun & 58 & 27,23 \\
\hline 11-15 Tahun & 27 & 12,68 \\
\hline$\geq 16$ Tahun & 32 & 15,02 \\
\hline Total & 213 & 100 \\
\hline
\end{tabular}

Tabel 2 menunjukkan bahwa mayoritas responden masih memiliki perilaku yang tidak aman pada saat bekerja $(51,64 \%)$, merasa pengawasan K3 di proyek masih kurang baik (54,93\%),
(58,69\%) terhadap kecelakaan kerja dan perilaku aman di tempat kerja, motivasi responden untuk menciptakan kondisi yang aman dan berperilaku aman di tempat kerja masih lemah $(55,87 \%)$

Tabel 2. Distribusi Responden Berdasarkan Perilaku Aman, Pengawasan K3, Pengetahuan Keselamatan Kerja dan Motivasi Berperilaku Aman

\begin{tabular}{lcc}
\hline \multicolumn{1}{c}{ Kategori } & Frekuensi (n) & Proporsi (\%) \\
\hline Perilaku Aman & & \\
$\quad$ Aman & 103 & 48,36 \\
$\quad$ Tidak Aman & 110 & 51,64 \\
\hline Pengawasan K3 & \multicolumn{2}{l}{} \\
$\quad$ Kurang Baik & 117 & 54,93 \\
$\quad$ Baik & 96 & 45,07 \\
\hline $\begin{array}{l}\text { Pengetahuan Keselamatan Kerja } \\
\quad \text { Kurang }\end{array}$ & 125 & 58,69 \\
$\quad$ Baik & 88 & 41,31 \\
\hline Motivasi Berperilaku Aman & 119 & 55,87 \\
$\quad$ Lemah & 94 & 44,13 \\
$\quad$ Kuat & 213 & 100 \\
\hline Total & pada kelompok usia $>32$ tahun (52,75\%), \\
Berdasarkan Tabel 3, proporsi perilaku & berpendidikan tinggi (51,35\%) dan bekerja
\end{tabular}


lebih dari 7 tahun sebagai buruh bangunan $(56,25 \%)$.

Tabel 3. Distribusi Perilaku Kerja Responden Berdasarkan Karakteristik Responden

\begin{tabular}{|c|c|c|c|}
\hline \multirow[b]{2}{*}{ Karakteristik Responden } & \multicolumn{3}{|c|}{ Perilaku responden $(n=213)$} \\
\hline & $\begin{array}{l}\text { Aman } \\
(n=103)\end{array}$ & $\begin{array}{c}\text { Tidak Aman } \\
\quad(n=110)\end{array}$ & Total \\
\hline \multicolumn{4}{|l|}{ Umur } \\
\hline \multirow{2}{*}{$\begin{array}{l}\leq 32 \text { Tahun } \\
>32 \text { Tahun }\end{array}$} & $55(45,08 \%)$ & $67(54,92 \%)$ & 122 (100\%) \\
\hline & $48(52,75 \%)$ & $43(47,25 \%)$ & $91(100 \%)$ \\
\hline \multicolumn{4}{|l|}{ Pendidikan } \\
\hline Rendah & $65(46,76 \%)$ & $74(52,24 \%)$ & 139 (100\%) \\
\hline Tinggi & $38(51,35 \%)$ & $36(48,65 \%)$ & $74(100 \%)$ \\
\hline \multicolumn{4}{|l|}{ Lama Kerja } \\
\hline$\leq 7$ Tahun & $49(41,88 \%)$ & $68(58,12 \%)$ & $117(100 \%)$ \\
\hline$>7$ Tahun & $54(56,25 \%)$ & $42(43,75 \%)$ & $96(100 \%)$ \\
\hline
\end{tabular}

Berdasarkan analisis bivariabel pada Tabel 4 ditemukan bahwa terdapat dua variabel yang memiliki hubungan bermakna dengan perilaku aman yaitu pengawasan kesehatan dan keselamatan kerja (PR=1,84; $\mathrm{p}=0,0000 ; 95 \%$ CI 1,38-2,46) dan pengetahuan keselamatan kerja (PR=1,45; p=0,0085; 95\% CI 1,10-1,90). Sedangkan variabel motivasi berperilaku aman tidak memiliki hubungan yang bermakna dengan perilaku aman $(p>0,05)$.

Tabel 4. Hubungan pengawasan $\mathrm{K} 3$, pengetahuan keselematan kerja dan motivasi berperilaku aman dengan periaku aman pada responden

\begin{tabular}{|c|c|c|c|c|c|c|}
\hline \multirow[b]{2}{*}{ Variabel } & \multirow[b]{2}{*}{$\begin{array}{l}\text { Aman } \\
(n=103)\end{array}$} & \multicolumn{5}{|c|}{ Perilaku $(n=203)$} \\
\hline & & $\begin{array}{l}\text { Tidak } \\
\text { Aman } \\
(\mathrm{n}=110)\end{array}$ & Total & PR & $\begin{array}{c}95 \% \\
\text { CI }\end{array}$ & $\mathbf{P}$ \\
\hline \multicolumn{7}{|l|}{ Pengawasan K3 } \\
\hline Kurang Baik & $41(35,04 \%)$ & $76(64,96 \%)$ & $117(100 \%)$ & 1,84 & $1,38-2,46$ & 0,0000 \\
\hline Baik & $62(64,58 \%)$ & $34(35,42 \%)$ & $96(100 \%)$ & & & \\
\hline \multicolumn{7}{|l|}{ Pengetahuan } \\
\hline Kurang & $51(40,80 \%)$ & $74(59,20 \%)$ & $125(100 \%)$ & 1,45 & $1,10-1,90$ & 0,0085 \\
\hline Baik & $52(59,09 \%)$ & $36(40,91 \%)$ & $88(100 \%)$ & & & \\
\hline \multicolumn{7}{|l|}{ Motivasi } \\
\hline Lemah & $54(45,38 \%)$ & $65(54,62 \%)$ & $119(100 \%)$ & 1,15 & $0,87-1,51$ & 0,3277 \\
\hline Kuat & $49(52,13 \%)$ & $45(47,87 \%)$ & $94(100 \%)$ & & & \\
\hline
\end{tabular}


Berdasarkan analisis multivariable pada Tabel 5, diketahui variabel yang paling berpengaruh dengan perilaku aman adalah pengawasan $\mathrm{K} 3(\mathrm{OR}=3,21$; $95 \% \quad \mathrm{CI}=1,809-5,681 ; \quad \mathrm{p}=0,000) \quad$ dan pengetahuan keselamatan kerja $(\mathrm{OR}=1,88$; 95\% CI=1,049-3,368; $\mathrm{p}=0,034)$. Jika dilihat dari nilai odds, responden yang memiliki persepsi pengawasan $\mathrm{K} 3$ yang baik maka
3,2 kali berperilaku lebih aman di proyek dibandingkan responden yang memiliki persepsi pengawasan K3 yang kurang baik. Beradasarkan hasil yang didapatkan, maka $\mathrm{Ho}$ ditolak dan $\mathrm{H}_{\mathrm{a}}$ diterima yaitu terdapat hubungan yang bermakna antara pengawasan kesehatan dan keselamatan kerja (K3) dengan perilaku aman pada buruh bangunan di Kabupaten Badung.

Tabel 5. Analisis Multivariabel Pengawasan K3, Pengetahuan Keselamatan Kerja dan Motivasi Berperilaku Aman dengan Perilaku Aman

\begin{tabular}{|c|c|c|c|c|c|c|}
\hline \multirow{3}{*}{ Variabel } & \multicolumn{2}{|c|}{ Perilaku Aman $(n=203)$} & \multicolumn{4}{|c|}{ Model Akhir } \\
\hline & \multirow{2}{*}{$\begin{array}{c}\text { Aman } \\
(n=103)\end{array}$} & \multirow{2}{*}{$\begin{array}{c}\text { Tidak } \\
\text { Aman } \\
(n=110)\end{array}$} & \multirow[b]{2}{*}{$\mathbf{P}$} & \multirow[b]{2}{*}{ OR } & \multicolumn{2}{|c|}{$95 \%$ CI for OR } \\
\hline & & & & & Lower & Upper \\
\hline \multicolumn{7}{|l|}{ Pengawasan K3 } \\
\hline Kurang Baik & $41(35,04 \%)$ & $76(64,96 \%)$ & 0,000 & 3,21 & 1,809 & 5,681 \\
\hline Baik & $62(64,58 \%)$ & $34(35,42 \%)$ & & & & \\
\hline \multicolumn{7}{|l|}{ Pengetahuan } \\
\hline Kurang & $51(40,80 \%)$ & $74(59,20 \%)$ & 0,034 & 1,88 & 1,049 & 3,368 \\
\hline Baik & $52(59,09 \%)$ & $36(40,91 \%)$ & & & & \\
\hline \multicolumn{7}{|l|}{ Motivasi } \\
\hline Lemah & $54(45,38 \%)$ & $65(54,62 \%)$ & 0,611 & 1,16 & 0,652 & 2,068 \\
\hline Kuat & $49(52,13 \%)$ & $45(47,87 \%)$ & & & & \\
\hline
\end{tabular}

\section{DISKUSI}

Berdasarkan hasil uji chi-square ditemukan bahwa pengawasan kesehatan dan keselamatan kerja $(p=0,0000)$ memiliki hubungan bermakna dengan perilaku aman. dimana responden yang memiliki persepsi pengawasan K3 kurang baik berpotensi 1,84 kali meningkatkan risiko berperilaku tidak aman pada responden dibandingkan responden yang memiliki persepsi pengawasan $\mathrm{K} 3$ baik ( $\mathrm{PR}=1,84)$.

Hasil penelitian ini sesuai dengan penelitian yang dilakukan oleh Jatmiko, dkk yang menunjukkan bahwa terdapat hubungan antara pengawasan dengan perilaku pemakaian APD $(\mathrm{p}=0,038)$. (Jatmiko, dkk, 2017)

Penelitian yang dilakukan Halimah menyatakan peran pengawas yang kurang mendukung akan cenderung menyebabkan pekerja berperilaku tidak aman, peran pengawas merupakan salah satu faktor yang mempengaruhi perilaku pekerja. (Halimah,2010).

Sedangkan penelitian yang dilakukan oleh Shiddiq, dkk menujukkan perilaku 
negatif disebabkan oleh kurangnya pengawasan oleh supervisor K3 dan kurangnya pekerja mengikuti instruksi SOP yang telah ditetapkan. (Shiddiq, dkk., 2014)

Hal tersebut dapat diakibatkan karena sikap manajemen yaitu sebagai pengawas memiliki peran dalam pembentukan sikap pekerja baik secara langsung maupun secara tidak langsung. (Fogarty \& Shaw, 2010)

Pengetahuan terhadap keselamatan kerja $\quad(p=0,0085)$ memiliki hubungan dengan perilaku aman, dimana responden yang memiliki pengetahuan keselamatan kerja yang kurang berpotensi 1,45 kali meningkatkan risiko berperilaku tidak aman pada responden dibandingkan responden yang memiliki pengetahuan keselamatan kerja yang baik $(\mathrm{PR}=1,45)$.

Hasil penelitian ini sesuai dengan penelitian yang dilakukan oleh Suriani yang menyatakan terdapatnya hubungan yang signifikan antara pengetahuan dengan perilaku aman karyawan (95\%; $p=0,004$ ). (Suriani, 2013)

Seseorang yang memiliki pengetahuan yang luas akan lebih bijak dalam memutuskan sesuatu tindakan. Sehingga pengetahuan memiliki pengaruh terhadap tindakan yang akan diambil. (Nani, 2009)

Motivasi untuk berperilaku aman ( $p=0,3277)$ tidak memiliki hubungan dengan perilaku aman pada responden. Hasil penelitian ini tidak sesuai dengan penelitian yang dilakukan oleh Halimah yang menyatakan bahwa terdapat hubungan antara motivasi dengan perilaku aman $(p=0,000)$. Walaupun memiliki hubungan, motivasi merupakan variabel yang tidak memiliki perbedaan bermakna dengan perilaku. Halimah, 2010)

Penelitian yang dilakukan oleh Sialagan mengungkapkan bahwa dorongan yang ada dalam diri tenaga kerja untuk berperilaku aman juga harus didukung perusahaan dengan penciptaan lingkungan yang memfasilitasi terjadinya perilaku aman di tempat kerja. Motivasi yang tinggi tanpa dukungan fasilitas dari perusahaan akan sekedar menjadi motivasi tanpa aktualisasi yang dapat meningkatkan tenaga kerja untuk berperilaku aman. (Sialagan, 2008)

Berdasarkan hasil analisis multivariabel, didapatkan hasil akhir bahwa, Pada pengawasan K3 ditemukan bahwa responden yang memiliki persepsi pengawasan K3 yang baik berpotensi 3,21 kali berperilaku lebih aman dibandingkan dengan responden yang memiliki persepsi pengawasan $\mathrm{K} 3$ yang kurang baik $(\mathrm{OR}=3,21 ; 95 \% \mathrm{CI}=1,809-5,681 ; \mathrm{p}=0,000)$.

Berdasarkan hasil uji regresi logistik, pengawasan K3 memiliki pengaruh paling besar dalam pembentukan perilaku aman pada pekerja konstruksi. Hasil ini didukung oleh penelitian yang dilakukan oleh Jatmiko, dkk yang menunjukkan bahwa adanya hubungan yang signifikan antara tingkat pengetahuan dengan perilaku pemakaian APD $(\mathrm{P}=0,018)$ dan pengawasan pekerja yang baik mempunyai kemungkinan dapat mempengaruhi terbentuknya perilaku pemakaian APD yang baik sebesar 9,04 kali dibanding pengawasan yang kurang (OR=9,04). (Jatmiko, dkk., 2017) 
Pada variabel pengetahuan keselamatan kerja menunjukkan bahwa responden yang memiliki pengetahuan keselamatan kerja yang baik berpotensi 1,88 kali berperilaku lebih aman dibandingkan dengan responden yang memiliki pengetahuan keselamatan kerja yang kurang (OR=1,88; 95\% CI=1,0493,368; $\mathrm{p}=0,034)$. Meskipun memiliki hubungan, Pengetahuan keselamatan kerja merupakan variabel yang tidak memiliki perbedaan bermakna terhadap perilaku aman. Hal ini diakibatkan oleh masih banyaknya pekerja yang melanggar peraturan perusahaan walaupun memiliki pengetahuan yang baik terhadap bahaya dan akibat dari bahaya tersebut terhadap dirinya.

Hasil ini didukung oleh penelitian yang dilakukan oleh Jatmiko, dkk menunjukkan bahwa adanya hubungan yang bermakna antara pengawasan K3 dengan perilaku pemakaian APD ( $\mathrm{P}=0,012)$. (Jatmiko, dkk., 2017). Hasil penelitian laing menyatakan pengetahuan yang baik memiliki peluang 7 kali perilaku amannya baik dari pada pengetahuan yang kurang $(\mathrm{OR}=6,618)$. (Suriani, 2013),

Pada variabel motivasi berperilaku aman menunjukkan tidak adanya hubungan yang bermakna antara variabel motivasi berperilaku aman dengan berperilaku aman $(\mathrm{P}=0,611)$.

Motivasi yang tinggi tidak menjamin pekerja akan berperilaku aman, hal ini dikarenakan ketidakpuasan pekerja terhadap pekerjaan mereka (Reward). Kurangnya reward menjadikan kurangnya faktor pendorong hal tersebut membuat motivasi pekerja menjadi lemah karena kurangnya faktor pendorong tersebut. (Halimah, 2010)

\section{SIMPULAN}

Berdasarkan pemaparan hasil, maka dapat disimpulkan bahwa karakteristik responden, sebagian besar pekerja berumur 24-34 tahun, berpendidikan terakhir SMP, dan bekerja selama 1-5 tahun. Mayoritas responden memiliki persepsi pengawasan K3 yang kurang baik, pengetahuan yang kurang terhadap keselamatan kerja, motivasi yang lemah terhadap berperilaku aman. Mayoritas responden memiliki perilaku tidak aman dengan proporsi lebih tinggi pada responden yang berumur $\leq 32$ tahun, berpendidikan rendah dan memiliki pengalaman kerja $\leq 7$ tahun. Perilaku aman berhubungan secara signifikan dengan pengawasan $\mathrm{K} 3$ dan pengetahuan tentang keselamatan kerja, sedangkan motivasi berperilaku aman tidak berhubungan secara signifikan dengan perilaku aman. Pengawasan K3 merupakan faktor yang paling berpengaruh terhadap perilaku aman pekerja.

\section{SARAN}

Adapun saran yang dapat diberikan kepada pekerja yaitu untuk selalu mengikuti dan menaati peraturan yang telah ditetapkan oleh perusahaan dan bagi pengawas selaku bagian dari manajemen disarankan untuk meningkatkan pengawasan kepada pekerja karena masih didapati pekerja yang merasa kurangnya pengawasan dari pengawas dan melakukan monitoring dan 
evaluasi terhadap perilaku kerja pekerja secara rutin.

\section{DAFTAR PUSTAKA}

Fogarty, G.J., \& Shaw, A. (2010). Safety climate and the Theory of Planned Behavior: Towards the prediction of unsafe behavior. 42, 1455-1459. doi:10.1016/j.aap.2009.08.008

Halimah, S. (2010). Faktor-Faktor Yang Mempengaruhi Perilaku Aman Karyawan Di PT SIM Plant Tambun II Tahun 2010. Universitas Islam Negeri Syarif Hidayahtullah Jakarta.

Jatmiko, F., Setiyawan, H., \& Atmojo, T. B. (2017). Hubungan antara Tingkat Pengetahuan dan Pengawasan terhadap Perilaku Pemakaian APD pada Pekerja Konstruksi PT Wika Beton Boyolali. Journal Of Industrial Hygiene And Occupational Health, 2, 44-56.

Https://Doi.Org/10.21111/Jihoh.V2i1.1 272

Martinez-Corcoles, M., Gracia, F., \& M.Piero, J. (2011). Leadership And Employees' Perceived Safety Behaviours In A Nuclear Power Plant: A Structural Equation Model. Safety Science, 49, 1118-1129.

Nani, P. S. (2009). Perilaku Pengendara Sepeda Motor Pada Remaja Tehadap Risiko Kecelakaan Lalu Lintas. Universitas Airlangga.

National Safety Council. (2011). Injury Facts (2011 Edition). Itasca, Illinois: Author.

Notoatmodjo, S. (2012). Pendidikan Dan Perilaku Kesehatan. Jakarta: Rineka Cipta.

Shiddiq, S., Wahyu, A., \& Muis, M. (2014).
Hubungan Persepsi K3 Karyawan Dengan Perilaku Tidak Aman Di Bagian Produksi Unit IV PT. Semen Tonasa. Jurnal MKMI, 110-116. Retrieved from https://media.neliti.com/media/public ations/229580-hubungan-persepsi-k3karyawan-dengan-per-a811cfd2.pdf' Sialagan, T. (2008). Analisis Faktor-Faktor Yang Berkontribusi Pada Perilaku Aman di PT EGS Indonesia Tahun 2008. Depok: FKM UI. Pp. 15-26.

Suriani, D. (2013). Faktor-Faktor yang Berhubungan dengan Perilaku Aman Karyawan di PLTU Nagan Raya. Universitas Teuku Umar

Workplace Safety and Health Institute. (2017). Global Estimates of Occupational Accidents and Work-related Illnesses 2017. Singapore. 